\title{
EFFECTS OF ACETYLACETONE ADDITIONS ON PZT THIN FILM
} PROCESSING

ROBERT W. SCHWARTZ, R. A. ASSINK, D. DIMOS, M. B. SINCLAIR, T. J. BOYLE, AND C. D. BUCHHEIT

Sandia National Laboratories

The Advanced Materials Laboratory

1001 University Blvd. SE, Suite 100

Albuquerque, NM 87106

\section{ABSTRACT}

Sol-gel processing methods are frequently used for the fabrication of lead zirconate titanate (PZT) thin films for many electronic applications. Our standard approach for film fabrication utilizes lead acetate and acetic acid modified metal alkoxides of zirconium and titanium in the preparation of our precursor solutions. This report highlights some of our recent results on the effects of the addition of a second chelating ligand, acetylacetone, to this process. We discuss the changes in film drying behavior, densification and ceramic microstructure which accompany acetylacetone additions to the precursor solution and relate the observed variations in processing behavior to differences in chemical precursor structure induced by the acetylacetone ligand. Improvements in thin film microstructure, ferroelectric and optical properties are observed when acetylacetone is added to the precursor solution.

\section{INTRODUCTION}

A variety of solution deposition methods have been employed for the fabrication of lead zirconate titanate (PZT) thin films.[1-4] Several of these methods have been used with considerable success in the preparation of films with acceptable dielectric and ferroelectric properties. However, a review of the literature demonstrates that, depending on the preparation method employed, films with different microstructural and electrical properties may be obtained. Further, film properties have also been observed to vary with simpler solution preparation variables, such as solution aging prior to film deposition. For example, we have observed that for films deposited from aged solutions, the tendency toward film cracking increases as does the coercive field.[5] Because of such observations it is evident that some aspect of the precursor solutions defines thin film processing. Control of such critical solution variables should permit the preparation of higher quality films in a more reproducible manner.

The most widely employed "sol-gel" methods fall into one of two general categories: (i) processes based on the use of the solvent 2-methoxyethanol;[2,6] and (ii) processes based on chelating ligands such as acetic acid[3,4] or ethanolamine compounds.[7,8] (Historically, metallo-organic decomposition (MOD) processes based on the use of other carboxylate and betadiketonate precursors have also been used.[9-11]) Considering that methoxyethanol serves not only as a solvent but also as a chelating ligand, we may state that the precursor species in both of the sol-gel categories are molecularly modified alkoxides. Recently, much information regarding the nature of these modified alkoxide species has been obtained. $[3,12,13]$ It is known that the precursor species are oligomeric in nature, and for the methoxyethanol[12] and acetic acid-based processes, $[3,13]$ possess bi-dentate bridging ligands. Structural information for similar species in simpler material systems has also been obtained by preparing crystalline compounds.[14]

In an attempt to understand the effects that precursor structural differences may exert on thin film processing behavior, i.e., consolidation, densification, and crystallization, we have systematically studied the effects of various chelating ligands on thin film processing in single component systems such as $\mathrm{TiO}_{2}[15]$ and $\mathrm{ZrO}_{2} \cdot[16]$ A summary of the critical precursor and ligand properties is outlined in Table $\mathrm{I}$. Precursor properties that serve to define film consolidation and densification behavior include: ligand steric size; accessibility to residual alkoxy species; hydrolysis behavior of alkoxy groups and modifying ligands; and ligand pyrolysis

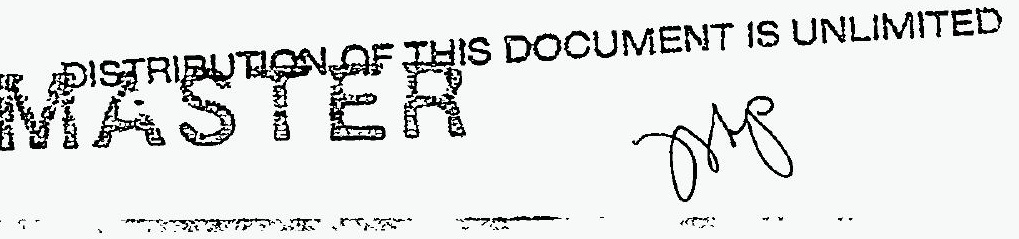




\section{DISCLAIMER}

Portions of this document may be illegible in electronic image products. Images are produced from the best available original document. 


\section{Table I.}

Effect of ligand characteristics on precursor properties and thin film processing behavior.

$\begin{array}{lll}\text { Ligand Property } & \text { Precursor Property Affected } & \text { Film Processing Behavior Affected } \\ \text { Steric size } & \begin{array}{l}\text { Accessibility to residual alkoxys } \\ \text { Opacity/transperancy } \\ \text { Reactivity }\end{array} & \begin{array}{l}\text { Aggregation and packing efficiency } \\ \text { Hydrolysis and condensation behavior }\end{array} \\ & \text { Chemical vs. physical gelation } & \\ \text { Pyrolysis Temp. } & \text { Reactivity } & \\ & & \begin{array}{l}\text { Retention of amorphous structure } \\ \text { Densification }\end{array} \\ & & \begin{array}{l}\text { Crystallization temperature } \\ \text { Crystallization behavior }\end{array}\end{array}$

behavior. Effects of precursor structure on crystallization behavior have also been noted.[13,17,18] However, they are less clearly understood than the relationships between precursor structure and film consolidation and densification. Although the pathways by which precursor structure/nature affects crystallization behavior are less clearly understood than for consolidation or densification, they are no less important in the successful processing of thin films.

In the present paper, we present an example that demonstrates the importance of modifying ligand properties/precursor structure on the processing of PZT thin films prepared by an acetic acid chelating agent method. Specifically, we discuss the changes in film processing behavior that are observed when a second chelating ligand, acetylacetone (acac; 2,4-pentanedione) is added to the standard acetic acid-based precursor solution. We compare the results for PZT thin film processing with and without acac additions to our previous studies on simpler material systems, where controlled variations in precursor structure were introduced. The importance of acac additions on the electrical and optical properties of the films are also considered. While the present paper only gives one example of the need to control precursor properties, it is important to recognize that our overall goal is to understand the effects of such intentionally introduced variations in precursor structure so that improved sol-gel fabrication routes may be developed.

\section{EXPERIMENTAL}

PZT thin films were fabricated by an inverted mixing order (IMO) sol-gel method. $[3,19,20]$ The precursor solutions were prepared by first mixing the appropriate amounts of zirconium butoxide-butanol* with titanium isopropoxide* and allowing 5 minutes for reaction. Acetic acid, ${ }^{*}$ approximate molar ratio $4.0 / 1.0$ mol alkoxide, was then added. After waiting 5 minutes for reaction, methanol $\neq$ was then added. Lead (IV) acetate* was then added and the solution was heated to $\sim 85^{\circ} \mathrm{C}$ for dissolution of the lead precursor. Solution preparation was completed with further additions of methanol, acetic acid and water. Typically, $0.4 \mathrm{M}, 50 \mathrm{ml}$ batches were prepared, and $10 \mathrm{~mol} \%$ excess lead acetate was added to the precursor batch to

\footnotetext{
* Aldrich Chemical Company, Inc.; Milwaukee, WI

$\ddagger$ Fisher Scientific; Pittsburgh, PA
} 
compensate for lead volatility during firing. Prior to film fabrication, we added acac $\ddagger$ to selected solution aliquots. Additions as high as three moles of acac per mole of PZT were investigated. The acac ligand was added to the IMO solution while stirring. Details of the approach have been discussed previously, $[3,19]$ as have results of investigations regarding the nature of the solution species.[20] Process optimization for thin film fabrication on $\mathrm{RuO}_{2}$ electrodes has also been discussed.[21]

Solution viscosities at $30^{\circ} \mathrm{C}$ were measured using a Koehler $\mathrm{K}-23300$ kinematic viscosity bath and calibrated Size 1 Ubbelodhe viscometer tubes. FTIR spectra of the solutions were obtained at a resolution of $4 \mathrm{~cm}^{-1}$ using a Nicolet Magna 550 spectrometer. $\mathrm{KBr}$ pellets were prepared by adding one drop of the standard IMO or acac-modified IMO solution to $0.6 \mathrm{~g}$ of $\mathrm{KBr}$. Dried powder samples were prepared for solid state $13 \mathrm{C}$ NMR analysis by vacuum distillation of the IMO or acac-modified IMO solution at $25^{\circ} \mathrm{C}$. Vacuum distillation results in the removal of both the solvent and by-product components of the solutions, and thus allows for a more direct study of the nature of the precursor species.

For the acac-modified solutions, thin films were prepared at various times after acac addition. Results are only presented, however, for films fabricated approximately 15 to 20 minutes after addition, since to date, those films displayed the best processing behavior. In the present case, the IMO solution was aged for 60 days prior to acac addition and film fabrication. Thin films were fabricated onto $\mathrm{Pt} / \mathrm{Ti} / \mathrm{SiO}_{2} / \mathrm{Si}$ substrates by spin-casting at $3000 \mathrm{rpm}$ for 30 seconds. After deposition of each layer, the sample was heat treated on a hot plate at $300^{\circ} \mathrm{C}$ for 5 minutes for pyrolysis of organic species. Fired films thicknesses (per layer) varied from $\sim 900 \AA$ to $\sim 1000 \AA$, depending upon the acac/PZT molar ratio. Thicker films were fabricated by a multilayering approach, and in general, four layers were deposited and pyrolyzed prior to crystallization. Crystallization was accomplished by heat treatment at $650^{\circ} \mathrm{C}$ for 30 minutes using a $20^{\circ} \mathrm{C} / \mathrm{min}$ ramp rate.

Film thickness and refractive index were measured by ellipsometry (Gaertner L116-C; $\lambda=6328 \AA$ ). Pyrolysis of organic species from the films was determined using a diffuse reflectance attachment accessory with the Nicolet Magna 550. Ferroelectric properties of the films were measured using a Radiant Technologies RT66A. Optical scattering losses were characterized by a specularly resolved reflectance technique.[22]

\section{RESULTS AND DISCUSSION}

\section{Reaction Chemistry Of Acac Additions}

We have previously used a variety of spectroscopic techniques to characterize the reaction chemistry of the IMO process.[3,20] While solution preparation by this route is relatively straightforward, the reaction chemistry of the process is, in reality, rather complex. Chelation, solvent reactions, e.g., esterification, and hydrolysis and condensation, were all found to play a critical role in the formation of the species that exist in the IMO precursor solutions.[20] By using both liquid and solid state ${ }^{13} \mathrm{C} \mathrm{NMR}$ we were able to determine the general nature of the precursor species in solution. The species were found to be oxo-acetate in nature, with nearly complete replacement of the original alkoxy groups of the starting reagents. These species may be represented by the general formula: $\mathrm{Pb}_{u}\left(\mathrm{Zr}_{v}, \mathrm{Ti}_{\mathrm{w}}\right) \mathrm{O}_{\mathrm{x}}(\mathrm{OAc})_{\mathrm{y}}(\mathrm{OR})_{\mathrm{z}}$, where $\mathrm{z}$ is significantly less than $y$. Also, in the present situation, it is most likely that the metal stoichiometry varies from precursor molecule to precursor molecule. The preparation of truly stoichiometric homogeneous precursors requires special synthetic techniques as discussed by Archer and coworkers.[23] However, it remains to be determined whether the synthesis of such homogeneous precursor species is actually required for the fabrication of films with acceptable properties.

To study the effect of adding a second chelating ligand (acac) to the IMO precursor solution, NMR and FTIR spectroscopy were again utilized. Shown in Figure 1 are the solid state 13C NMR spectra of dried IMO and acac-modified IMO solutions. It is evident in Figure la, that the IMO precursor species display only two strong peaks. These are associated with the carboxylic $(\sim 180 \mathrm{ppm})$ and methyl $(\sim 25 \mathrm{ppm})$ carbons of the acetate ligand. As discussed above, the implication of this result is that the majority of the alkoxy ligands of the titanium and zirconium starting compounds have been replaced by chelation and other reactions. 


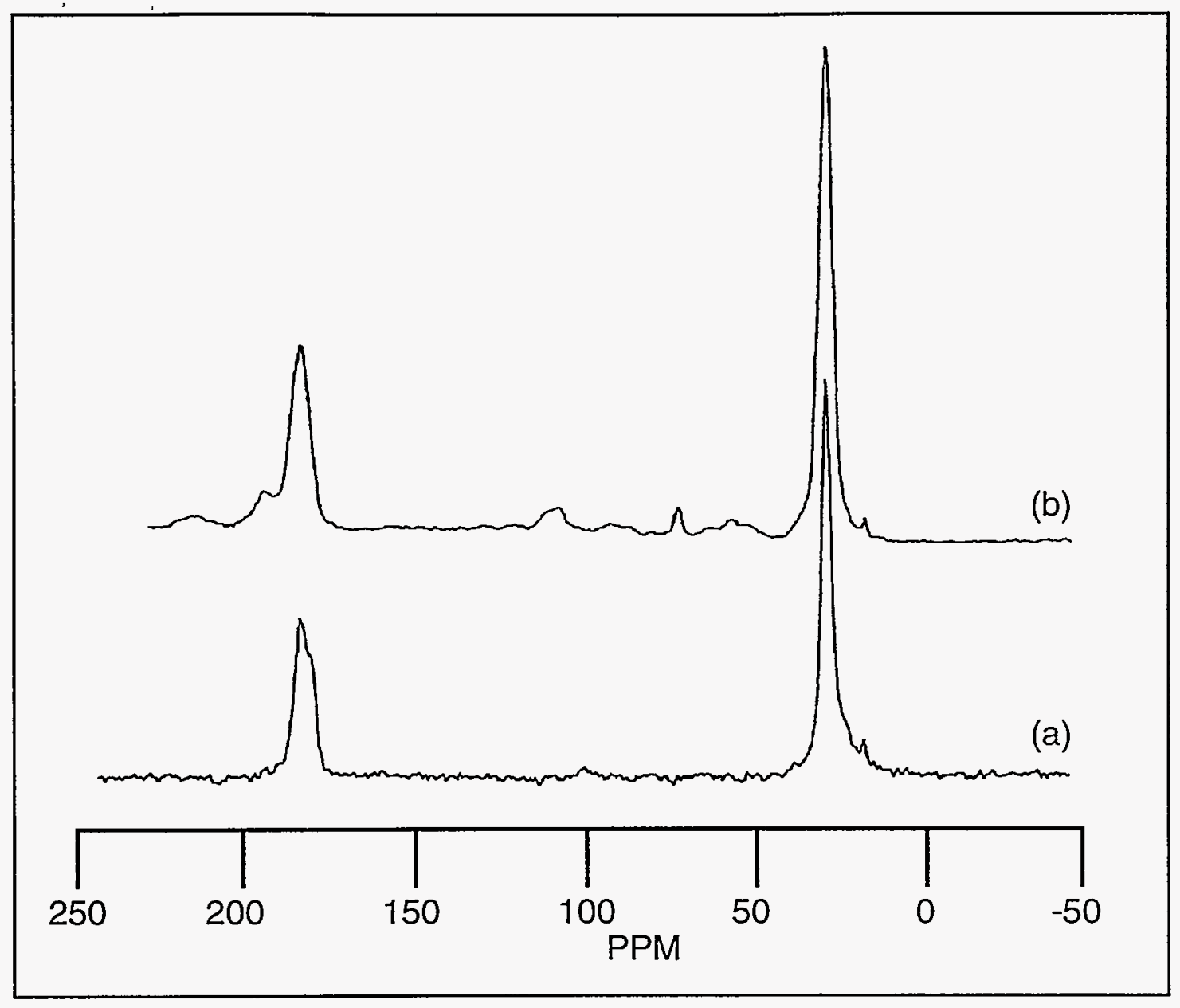

Figure 1. Solid state ${ }^{13} \mathrm{C}$ NMR of powders derived from (a) IMO and (b) acac-modified IMO solutions. See text for details of sample preparation.

While acac is reported to be a stronger chelating agent than acetate,[24] since the IMO precursor species are already highly chelated by acetate, we wanted to confirm that when acac was added to the solution that it would still chelate the precursor species as predicted. The results illustrated in Figure $1 \mathrm{~b}$ indicate that acac does in fact still act as a chelating ligand in this scenario. While the methyl and carboxylic carbon peaks of the chelated acac ligand overlap with the methyl and carboxylic carbon peaks of acetate, the peak at $\sim 102 \mathrm{ppm}$ is due to the methine caibon of the enol form of acac, the form that is expected when acac is bound to a metal.[25] We believe that the presence of this peak indicates that the oxo-acetate species produced in the IMO process are indeed chelated by acac, and are modified at the molecular level by the introduction of acac to the solution.

We have also looked at the time dependence of the acac chelation reaction. Shown in Figure 2 are the FTIR spectra of an aged IMO solution, an acac-modified IMO solution 25 minutes after acac addition, and the same acac-modified IMO solution 2 hours and 25 minutes after acac addition. Spectral regions of particular interest include the M-O region $(\sim 450-500$ $\left.\mathrm{cm}^{-1}\right)$ and the C-O region $\left(\sim 1200-1800 \mathrm{~cm}^{-1}\right)$. For the aged IMO solution, in the M-O vibrational region we see two distinct peaks at $455 \mathrm{~cm}^{-1}$ (strong) and $475 \mathrm{~cm}^{-1}$ (weak). With addition of acac, after 25 minutes a significant broadening in this spectral region occurs, with only one peak observed at $475 \mathrm{~cm}^{-1}$. We interpret this as confirmation not only of acac chelation, but also of a change in the molecular (backbone) nature of the precursor species. In the $\mathrm{C}-\mathrm{O}$ spectral region, after 25 minutes we also observe a new peak at $\sim 1385 \mathrm{~cm}^{-1}$ which is most likely also indicative of chelated acac $\left(\delta\left(\mathrm{CH}_{3}\right)\right.$ acac $\left.\sim 1380 \mathrm{~cm}^{-1}\right)$.[26] 


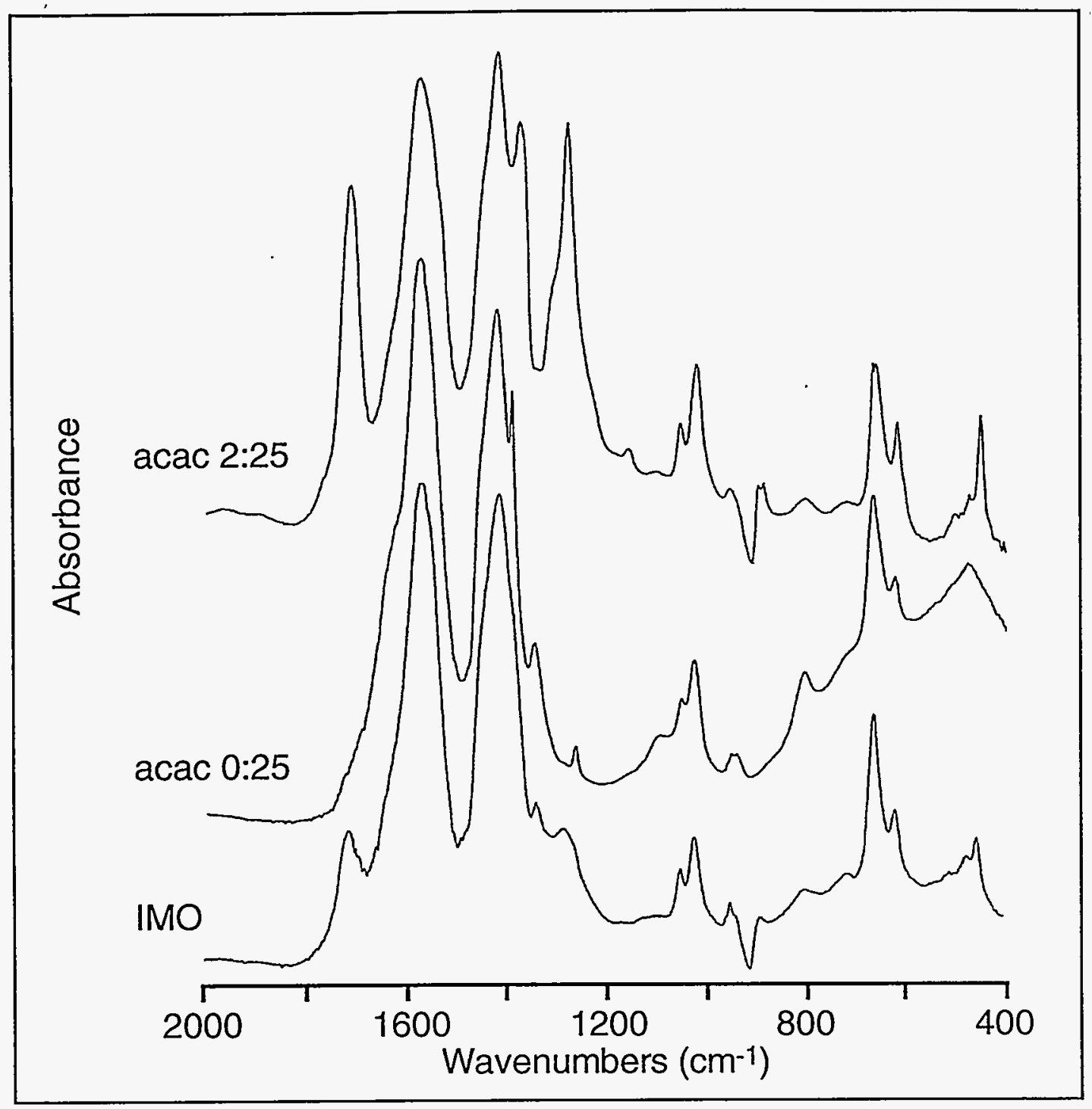

Figure 2. FTIR spectroscopy of aged (60 day) IMO and acac-modified IMO deposition solutions. Times indicated are after addition of acac to IMO solution.

With longer reaction times ( 2 hours, 25 minutes) spectral features in both reginns change dramatically: the $\mathrm{M}-\mathrm{O}$ region again displays two separate, sharp peaks at $455 \mathrm{~cm}^{-1}$ and $475 \mathrm{~cm}^{-1}$, as observed for the original, aged IMO solution; and the C-O spectral region shows the presence of two new intense bands at $1713 \mathrm{~cm}^{-1}$ and $1277 \mathrm{~cm}^{-1}$. Based on their peak positions and separation $\left(\Delta \sim 446 \mathrm{~cm}^{-1}\right)$ these bands are tentatively assigned to the asymmetric and symmetric stretches of the acetate ligand, present in a unidentate coordination, as reported previously by other investigators.[27,28] Due to the absence of a peak at $1770 \mathrm{~cm}^{-1}$, a less likely assignment for the bands is that they are due to free acetic acid, which displays peaks at $\sim 1718 \mathrm{~cm}^{-1}$ and $1295 \mathrm{~cm}^{-1}$. In either case, the FTIR spectra indicate that the nature of the acac-modified solution species changes rapidly with time after acac addition. We consider these changes in FTIR spectral features (i.e., the changes in precursor structure/solution characteristics) because they have a significant impact on thin film processing behavior, as discussed below.

\section{Variations In Thin Film Processing Behavior}

To study the effects of variations in precursor nature on thin film processing behavior we generally utilize several techniques. One of the methods we employ is to determine the dependence of kinematic solution viscosity on concentration, which gives an indication of the 
extent of oligomer/polymer interactions in the solution.[29] For the $\mathrm{MMO}$ and acac-modified IMO solutions we determined that the viscosity-concentration dependence of both solutions was very similar; solution viscosities varied from about $0.7 \mathrm{cs}$ at $0.05 \mathrm{M}$ to about $1.5 \mathrm{cs}$ at $0.4 \mathrm{M}$. Only at the highest concentration did the acac-modified solution display a noticeable greater viscosity, $\sim 1.5 \mathrm{cs}$ compared to $\sim 1.4 \mathrm{cs}$ for the IMO solution. Therefore, at the length (or interaction) scales present in solution, differences in the nature of the interaction of the precursor species only become slightly apparent at higher concentration. Interestingly, this result parallels that for acacbased versus acetate-based solutions used in zirconia thin film fabrication.[16] In this material system, both precursor solutions displayed similar viscosity-concentration dependencies and only at $0.4 \mathrm{M}$ did the viscosity of the acac-based solution significantly exceed that of the acetate based solution ( $>2.6 \mathrm{cs}$ vs. $<2.5 \mathrm{cs}$ ). Thus, in different material systems, we observe similar ligand effects on precursor interactions in the coating solutions.

Other similarities in thin film fabrication between the zirconia and PZT material systems were also noted. Figure 3 presents results for ellipsometry measurements of the changes in film thickness and refractive index as a function of drying time at room temperature for IMO and acacmodified IMO films. With acac modification of the precursor species, initial, as-deposited film thickness increased greatly, from $\sim 4400 \AA$ to $\sim 8100 \AA$ (see Figure $3 a$ ). At the same time, the initial refractive index of the acac-modified IMO film also decreased substantially, from $\sim 1.55$ for the standard IMO film to $\sim 1.20$ (see Figure 3b). Compared to the solution viscosity results, the differences in precursor characteristics introduced by the acac modification became much more evident as the "scale" of the interaction changes from the solution level $(0.4 \mathrm{M})$ to the thin film level, where aggregation of solution species begins and concentration rapidly increases during the spin-off stage of the deposition. We believe that the greater initial film thickness and lower initial refractive index of the acac-modified IMO film are due to a change in the aggregation behavior/packing efficiency of the precursor species. The acac-modified IMO species evidently pack less efficiently during film formation that the IMO species, resulting in a film of greater thickness and lower index.

Also evident in Figure 3 is the fact that both films display extensive consolidation with "drying" time at room temperature. Due to the greater initial thickness of the acac-modified IMO film, this film consolidates to a much greater extent than the standard IMO film (73\% versus 36\% shrinkage). In addition, we also believe that the greater consolidation of the acac-based film is related to acac being a sterically larger, less hydrolyzable ligand than acetate.[24] This has two effects: first, the greater steric bulk of the acac ligand limits accessibility to any residual reactive alkoxy ligands; second, since acac itself is a less hydrolyzable ligand, precursor reactivity toward hydrolysis and condensation is further minimized. Less reactive, i.e., more transparent species, show less tendency toward crosslinking during deposition, resulting in films which display greater shrinkage during drying since the species interpenetrate to a greater extent.[16,30] These differences in precursor and film nature have implications for subsequent processing behavior, i.e., densification, as discussed later.

The results for initial thickness, initial refractive index, and shrinkage for the acacmodified and standard IMO films again mimic those for zirconia films fabricated from acac and acetate based precursors.[16] In this material system, films prepared from acac-based precursors displayed a greater initial thickness $(\sim 2400 \AA$ vs. $\sim 2150 \AA)$, lower refractive index $(\sim 1.455$ vs. $\sim 1.481$ ) and greater shrinkage (40\% vs. $26 \%$ ) than films prepared from acetate-based precursors. As observed for solution viscosity, effects of ligand modification on thin film processing appear to be consistent between simple material systems, such as zirconia, and complex materials systems, such as PZT.

While differences in film drying behavior for films fabricated from the two precursor solutions are interesting, of greater importance is that the crystallization behavior of the films is affected. Illustrated in Figure 4 are surface and cross-sectional photomicrographs of typical thin films prepared from an aged IMO solution (Figure 4a) and from an acac-modified, aged IMO solution (Figure 4b). Without acac addition, films prepared from aged IMO solutions typically display microstructures that are defined by two nucleation events: nucleation of small $(\sim 100 \mathrm{~nm})$ columnar grains at the lower platinum electrode, and nucleation of larger $(\sim 1 \mu \mathrm{m})$ spherical grains at the surface of the film. The incidence of surface nucleation typically increases with solution aging; while fresh solutions yield films characterized by a few surface-nucleated grains, aged solutions display a significantly higher frequency of surface-nucleated grains, as shown in Figure 
(a)

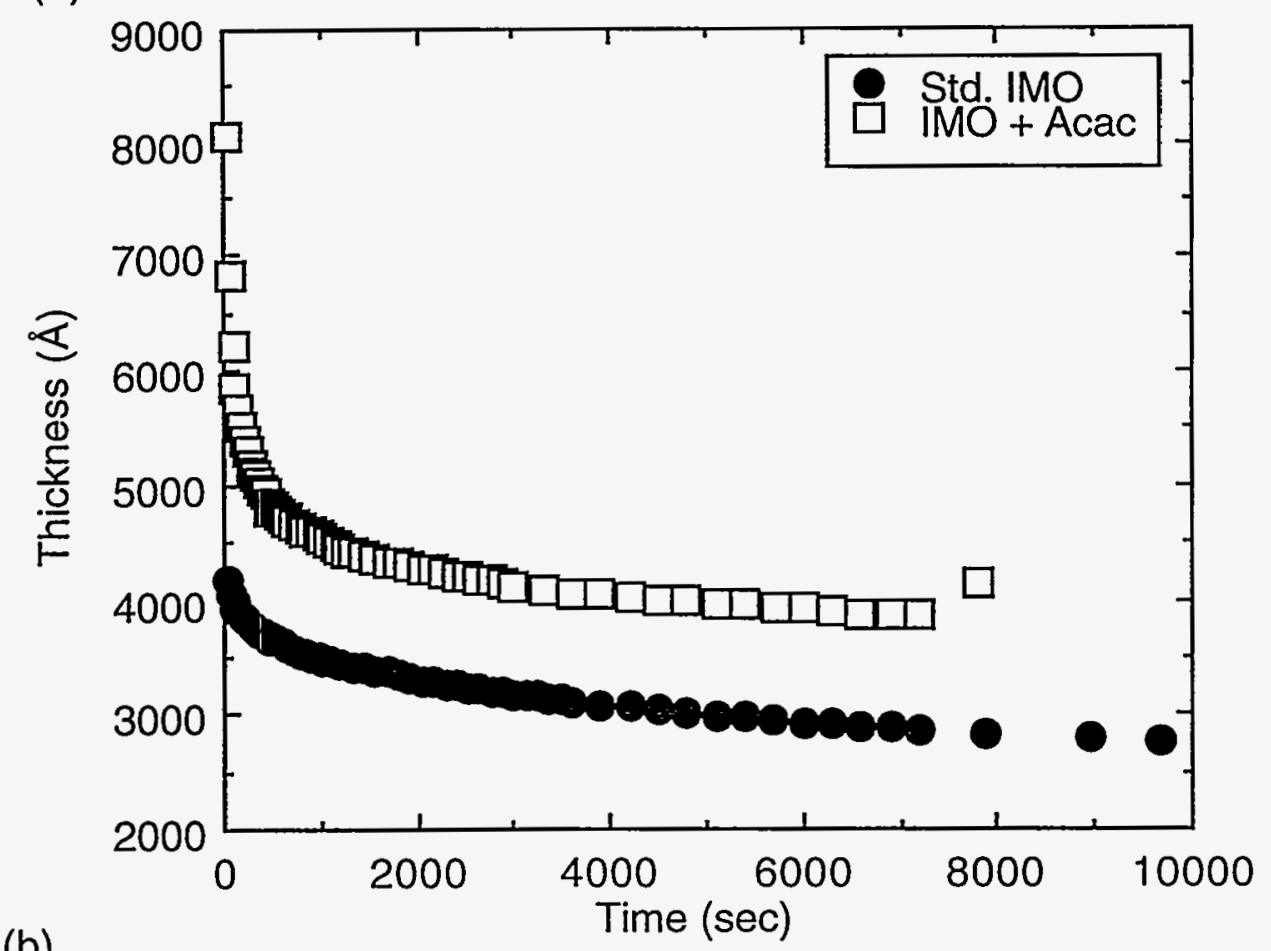

(b)

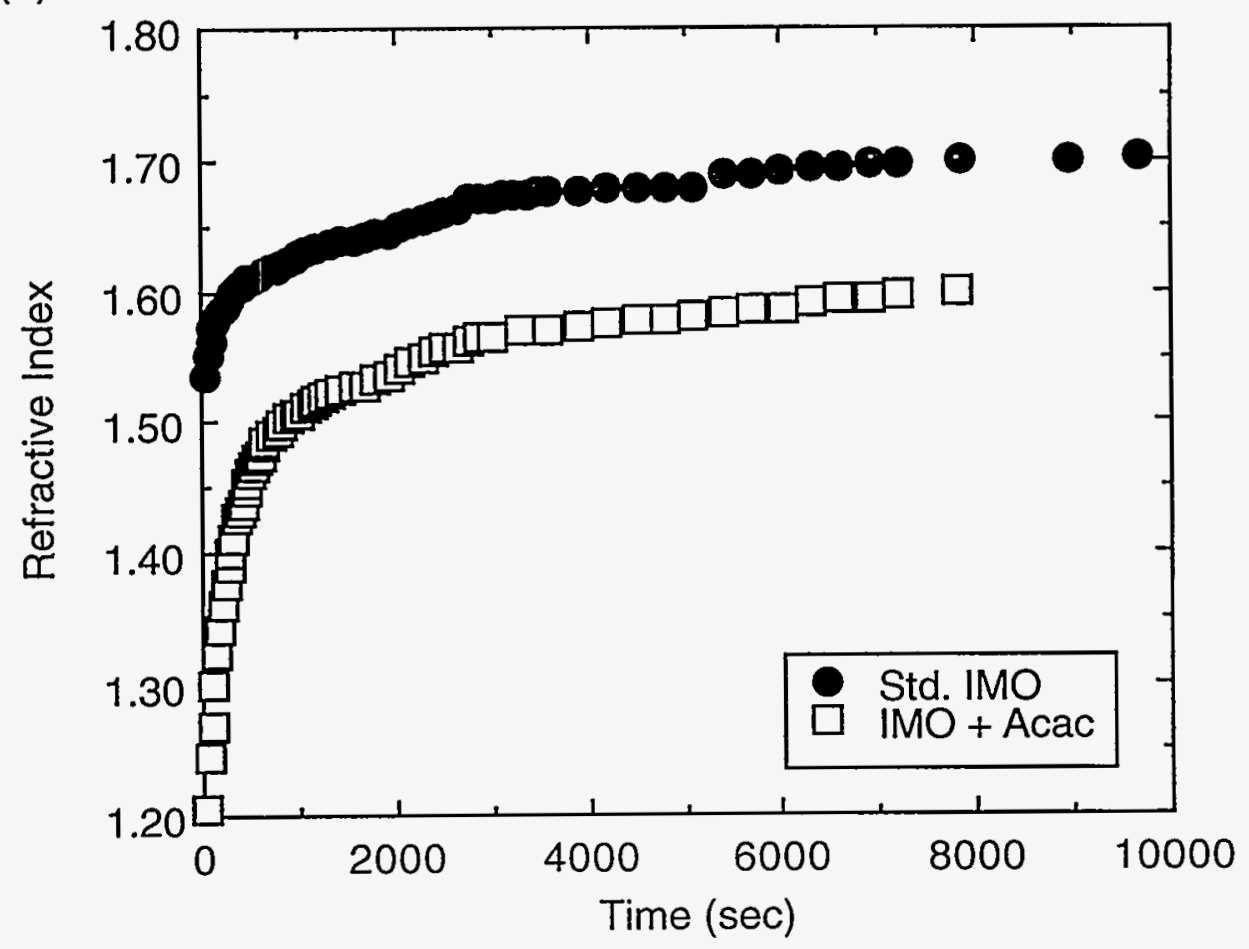

Figure 3. Ellipsometry measurements of (a) thickness and (b) refractive index for standard IMO and acac-modified IMO derived thin films; single layer PZT 40/60 thin films prepared on Si substrates.

4a. While grains of both types are perovskite in nature, because of the two nucleation events, the ceramic microstructure possesses a "di-phasic" morphology. The impact of this second, surface nucleation event on optical scattering losses is significant (see below).

Interesting, acac additions to aged IMO solutions result in a decreased frequency of surface-nucleated perovskite grains. For additions of 1 to 2 moles of acac per mol of PZT, surface nucleation is decreased, and for additions of 3 moles of acac per mol of PZT, surface 

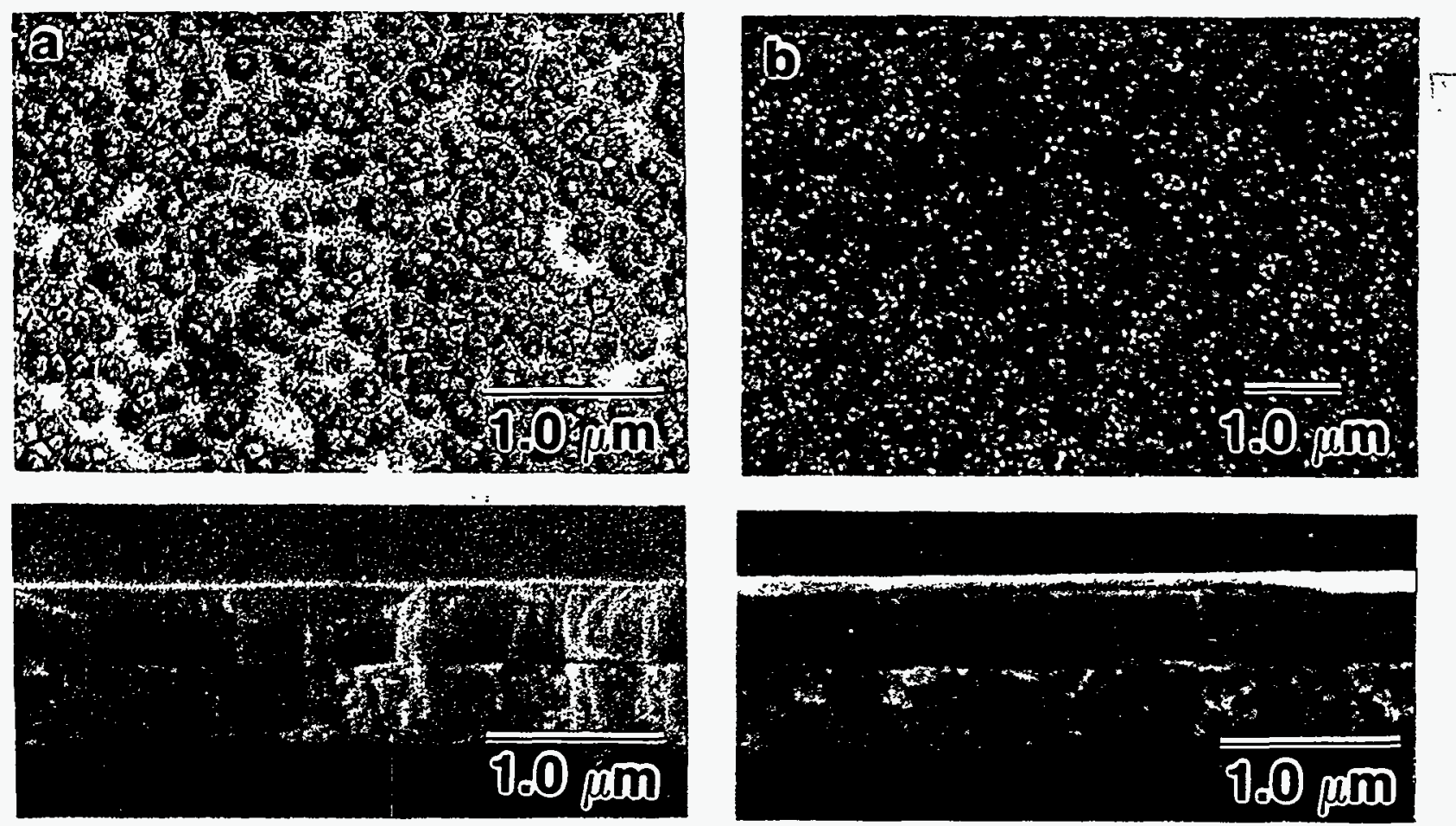

Figure 4. (a) Plan-view and cross-sectional SEM photomicrographs of a four layer PZT 40/60 film prepared from a standard IMO solution aged 60 days; (b) plan-view and cross-sectional SEM photomicrographs of a four layer PZT film prepared from the same 60 day old solution to which acetylacetone ( 3 moles/mole PZT) was added immediately prior to film fabrication. For crosssectional views: lower layer - Pt bottom electrode; second layer - PZT thin film; upper layer - Pt top electrode ((b) only).

nucleation can essentially be eliminated, as shown in Figure $4 \mathrm{~b}$. The resulting thin film microstructure is much more uniform since it is now completely defined by the heterogeneous nucleation event at the interface with the platinum electrode. While this example is somewhat of an extreme case, i.e., we know that fresh solutions can yield films with very few surfacenucleated grains, it serves to illustrate the point that variations in solution (precursor) characteristics can have a significant impact on thin film properties, and particularly, thin film crystallization behavior. The reasons for the change in nucleation behavior with acac addition are not completely understood at this time, however, it is believed that the elimination of the surface nucleation event is potentially related to the higher pyrolysis temperature of the acac ligand compared to the acetate ligand.[14] Further work remains to be carried out to truly define the mechanistic pathways by which such differences occur.

Before discussing the implications of such microstructural differences on the ferroelectric and optical properties of the films, two further comments need to be made. Above, the variation in the FTIR spectra of the acac-modified IMO solutions as a function of time were discussed. We have found that these differences correspond to differences in thin film processing behavior. Our highest quality acac-modified films were prepared shortly ( $<30$ minutes) after addition of acac to the IMO solution, regardless of whether or not the IMO solution was aged. Thus, these films were prepared from solutions that displayed a single broad peak in the M-O spectral region. Aging of the acac-modified solutions, even for only a few hours, resulted in the fabrication of films that were highly cracked.[31] Presumably, this is due to: (i) more extensive chelation of acac to the IMO precursors; (ii) conversion of a higher percentage of original bidentate acetate ligands to unidentate coordination; and (iii) as a result of these reactions, the generation of precursor species which do not possess adequate reactivity to yield a film capable of withstanding the stresses generated during low temperature heat-treatment. Thus, while precursors with minimal reactivity are desired in terms of preparing thin films which can be densified, a certain amount of precursor reactivity is required to yield a film with sufficient crosslinking and strength to survive subsequent processing. 


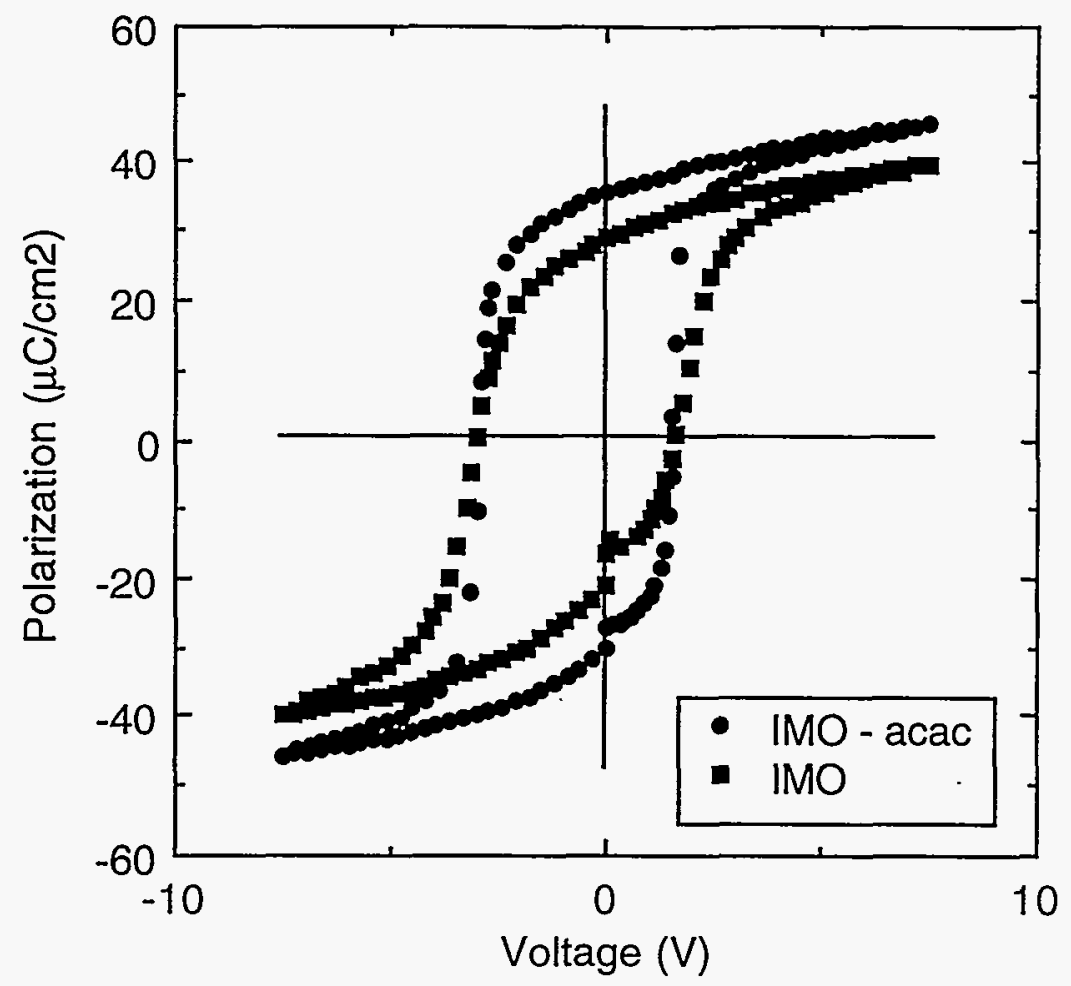

Figure 5. Ferroelectric hysteresis loops of $\sim 0.4 \mu \mathrm{m}$ PZT $40 / 60$ thin films prepared from IMO and acac-modified IMO solutions. Acac modified film prepared with 3 moles of acac per mole of PZT. Films heat-treated at $650^{\circ} \mathrm{C}$ for 30 minutes.

\section{Thin Film Electrical And Optical Properties}

As expected, improvements in film performance characteristics accompany the improvements in thin film microstructure that result from acac addition. Figure 5 shows typical ferroelectric properties for standard IMO and acac-modified IMO PZT 40/60 thin films. Films prepared from the acac-modified solutions displayed sharper coercive fields, and higher remanent and saturation polarizations. These results are expected based on the elimination of grain boundaries between the surface grains and the columnar grains.

Improvements in optical scattering losses were also observed to occur with acac modification, as shown in Figure 6. These results were obtained using a specularly resolved light scattering technique.[22] To compare the scattering losses of the respective films, analogous maxima or minima in the spectra should be considered. With the addition of 2 moles of acac per mole of PZT the scattering losses of the films are reduced by approximately one order of magnitude. This change is accompanied by a change in the visual appearance of the films from slightly hazy to specular. Dramatic improvements in scattering losses thus result from acac addition to the solution and the resulting elimination of surface nucleation. These results have implications for the development of these materials for optical storage devices, where attenuation and scattering losses are critical.

It is also evident from the scattering data (Figure 6) that the periodicity of the scattering curves changes as a function of acac addition. This observation is indicative of a corresponding variation in film thickness as a function of increasing acac modification; greater acac modification results in thinner films. As acac addition is increased from 0 to 2 moles of acac per PZT, film thickness decreased from $\sim 1000 \AA$ per layer to $\sim 900 \AA$ per crystallized layer. The acac-modified films thus densify to a greater extent than the standard IMO films, most likely as the result of decreased precursor reactivity. 


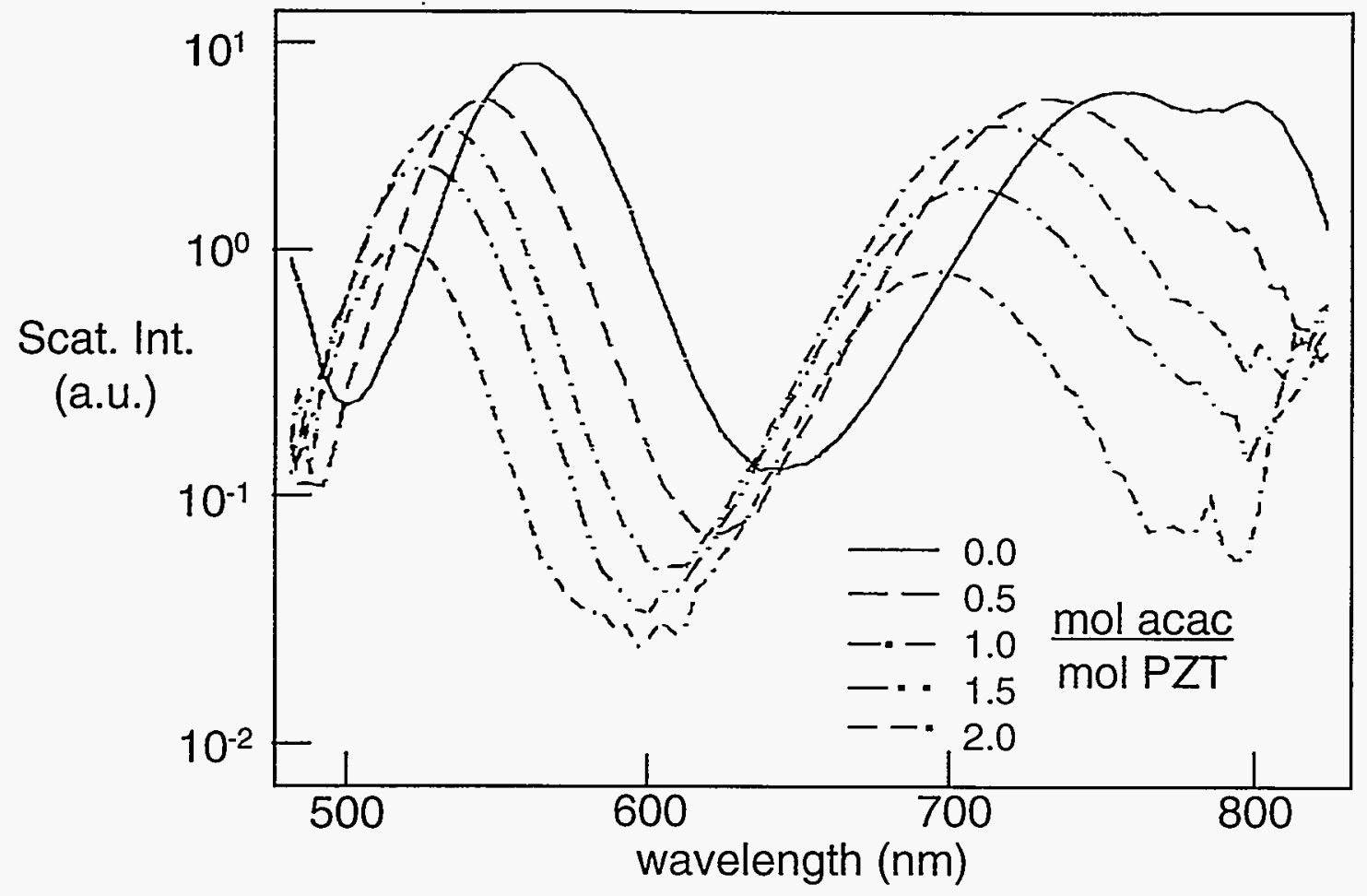

Figure 6. Optical scattering losses of PZT $40 / 60$ thin films prepared from IMO solutions with different levels of acacH incorporation. 24

\section{CONCLUSIONS}

PZT thin film processing, i.e., consolidation, densification, and crystallization may be controlled by tailoring precursor structure/nature through the use of chelating ligands with different properties. Ligand steric size, reactivity, and pyrolysis behavior are all thought to influence film processing behavior. As ligand steric size increased, as-deposited film thickness increased significantly, indicating a lower packing efficiency of the oligomeric solution species. Consolidation behavior was also found to depend on ligand size and reactivity. The acacmodified solutions resulted in films that consolidated to a greater extent. Finally, the higher pyrolysis temperature of the acac-modified IMO precursors was believed to be related to the elimination of the surface nucleation of larger perovskite grains. Similar ligand effects to those observed in this study of PZT film processing have also been noted in single component transition metal oxide film processing. Therefore, such ligand effects may be generic, and it may be possible to utilize an understanding of those effects to develop improved processing routes.

\section{ACKNOWLEDGEMENTS}

This work was performed at Sandia National Laboratories, supported by the U. S. Department of Energy under contract \# DE-AC04-94AL85000.

\section{REFERENCES}

1. See for example, Ferroelectric Thin Films II, edited by A. I. Kingon, E. R. Myers, and B. Tuttle, (Mat. Res. Soc. Symp. Proc. 243, Pittsburgh, PA, 1992).

2. K. D. Budd, S. K. Dey, and D. A. Payne, Brit. Ceram. Soc. Proc. 36, 107 (1985).

3. R. W. Schwartz, B. C. Bunker, D. B. Dimos, R. A. Assink, B. A. Tuttle, D. R. Tallant, and I. A. Weinstock, Int. Ferroelectrics 2, 243 (1992). 
4. G. Yi, Z. Wu, and M. Sayer, J. Appl. Phys. 64 (5), 2717 (1988).

5. C. D. Buchheit, T. J. Boyle, and R. W. Schwartz, unpublished results.

6. C. D. E. Lakeman, J.-F. Campion, and D. A. Payne, in Ceramic Trans. 25, 411 (1992).

7. Y. Takahashi and K. Yamaguchi, J. Mat. Sci. 25, 3950 (1990).

8. Y. Takahashi, Y. Matsuoka, K. Yamaguchi, M. Matsuki, and K. Kobayashi, J. Mat. Sci. 25, 3960 (1990).

9. J. Fukushima, K. Kodaira, and T. Matsushita, J. Mater. Sci. 19, 595 (1984).

10. R. W. Vest and J. Xu, Ferroelectrics 93, 21 (1989).

11. G. H. Haertling, Ferroelectrics 116, 51 (1991).

12. C. D. E. Lakeman, Ph.D. Thesis, University of Illinois at Urbana-Champaign (1994).

13. R. W. Schwartz, T. J. Boyle, S. J. Lockwood, M. B. Sinclair, D. Dimos, and C. D. Buchheit, Integrated Ferroelectrics, accepted for publication (1994).

14. R. W. Schwartz, J. A. Voigt, T. A. Christenson, T. J. Boyle, and C. D. Buchheit, to be published in Ceramic Engineering \& Science Proceedings (1995).

15. T. M. Alam, T. J. Boyle, C. D. Buchheit, T. W. Schwartz, and J. W. Ziller in Better Ceramics Through Chemistry VI, edited by A. K. Cheetham, C. J. Brinker, M L. Mecartney, and C. Sanchez, (Mat. Res. Soc. Symp. Proc. 346, Pittsburgh, PA, 1994). pp. 35-40.

16. R. W. Schwartz, J. A. Voigt, C. D. Buchheit, and T. J. Boyle, Ceramic Trans., Ferroic Materials: Design, Preparation and Characteristics 43, 145 (1994).

17. L. F. Francis and D. A. Payne, in Ferroelectric Thin Films, edited by E. R. Myers, and A. I. Kingon, (Mat. Res. Soc. Symp. Proc. 200, Pittsburgh, PA, 1992) pp. 173-178.

18. H. M. Jang, M. K. Cho, and B. D. Yoo, this proceedings.

19. R. W. Schwartz, R. A. Assink, and T. J. Headley, in Ferroelectric Thin Films II, edited by A. I. Kingon, E. R. Myers, and B. Tuttle, (Mat. Res. Soc. Symp. Proc. 243, Pittsburgh, PA, 1992) pp. 245-254.

20. R. A. Assink and R. W. Schwartz, Chem. Mat. 5 (4), 511 (1993).

21. S. J. Lockwood, R. W. Schwartz, B. A. Tuttle, and E. V. Thomas, in Ferroelectric Thin Films III, edited by E. R. Myers, B. A. Tuttle, S. B. Desu, and P. K. Larsen (Mat. Res. Soc. Symp. Proc. 310, Pittsburgh, PA) pp. 275-280.

22. M. B. Sinclair, D. Dimos, B. G. Potter, and R. W. Schwartz, J. Am. Ceram. Soc. (1995) in press.

23. C. D. Chandler, C. Roger, and M. J. Hampden-Smith, Chem. Rev. 93, 1205 (1993).

24. C. Sanchez, F. Babonneau, S. Doeuff, and A. Leaustic, in Ultrastructure Processing of Advanced Ceramics, edited by J. D. Mackenzie and D. R. Ulrich (Wiley Interscience, New York, 1988) pp. 77-87.

25. C. J. Pouchert and J. Sehnke, The Aldrich Library of $13 \mathrm{C}$ and $1 \mathrm{H}$ FT-NMR Spectra, Edition I I (1993) p. 661B.

26. A. Leaustic, F. Babonneau, and J. Livage, Chem. Mat. 1, 240 (1989).

27. S. Doeuff, M. Henry, C. Sanchez, and J. Livage, J. Non-Cryst. Sol. 89, 206 (1987).

28. K. H. Von Thiele, and M. Panse, Z. Anorg. Allg. Chem. 441, 23 (1978).

29. R. J. Young, Introduction to Polymers (Chapman Hall, New York, 1981) pp. 123 - 128.

30. C. J. Brinker, T. L. Ward, R. Sehgal, N. K. Raman, S. L. Hietala, D. M. Smith, D.-W. Hua, and T. J. Headley, J. Membane Science 77, 165 (1993).

31. C. D. Buchheit and R. W. Schwartz, unpublished results.

\section{DISCLAIMER}

\footnotetext{
This report was prepared as an account of work sponsored by an agency of the United States
Government. Neither the United States Government nor any agency thereof, nor any of their
employees, makes any warranty, express or implied, or assumes any legal
bility for the accuracy, con bility for the accuracy, completeness, or usefulness of assumes any legal liability or responsience herein to any or represents that its use would not infringermation, apparatus, product, or ence herein to any specific commercial product, process, or inge privately owned rights. Refermendation, or favoring does not necessarily constitute or imply its and opinions favoring by the United States Government or imply its endorsement, recomUnited States Governmers expressed herein do not necessarily any agency thereof. The views United States Government or any agency thereof.
} 